\title{
The Journey from Data to Qualitative Inductive Paper: \\ Who Helps and How?
}

\author{
Špela Trefalt* \\ Simmons College, School of Management \\ 300 The Fenway \\ Boston, MA
}

Phone: 617-521-3823

Email: spela.trefalt@simmons.edu

\author{
Marya L. Besharov \\ ILR School, Cornell University \\ 397 Ives Faculty Building \\ Ithaca, NY \\ Phone: 607-255-8524 \\ Email: mlb363@cornell.edu
}

Final draft of chapter to appear in Handbook of Innovative Qualitative Research Methods, Edited by Kimberly D. Elsbach and Roderick M. Kramer

October 21, 2014

* Both authors contributed equally 


\title{
The Journey from Data to Qualitative Inductive Paper: \\ Who Helps and How?
}

\begin{abstract}
How do qualitative inductive researchers move from raw data to publishable paper? Existing scholarly resources focus on how to analyze data more deeply and write it up to make a compelling contribution. Much less discussed but also critical is how researchers enlist others in the journey from data to paper - even when they are single authors of their work. Our chapter uncovers qualitative researchers' helpers and the types of help they provide. Drawing on data from detailed accounts of single authored qualitative, inductive studies, we explain the role of qualitative and quantitative scholars, peers and hired professionals, field informants and journal editors. We talk about help with theorizing, paper structure, emotional support, efficiency enhancement, and process guidance, and we offer practical tips for seeking these different forms of help throughout the research journey.
\end{abstract}


When a qualitative inductive researcher leaves the field, he or she faces mountains of data and a blank computer screen. Recognizing that the road to producing a paper is often long and difficult, scholars have written a number of texts aimed at helping new and seasoned researchers navigate the journey from data collection to publication. Most of this work focuses on collecting better data, analyzing it more deeply and comprehensively, and writing it up in ways that articulate compelling theoretical contributions (e.g., Becker, 1998; Carlson \& Dutton, 2011; Given, 2008; Glaser \& Strauss, 1967; Golden-Biddle \& Locke, 2007; Locke, GoldenBiddle, \& Feldman, 2008; Lofland \& Lofland, 1995; Pratt, 2009; Strauss \& Corbin, 1998; Van Maanen, 1988; Weiss, 1995). Yet it is well known that we do not travel alone on the road from data to paper, even when we are single authors of our work. To produce exemplary papers, we enlist others to help us make sense of our data and write up our work for publication. We engage trusted colleagues in conversations and consultations, and we organize ourselves into groups and communities to provide venues for social support.

Despite their importance, these forms of help have received little systematic attention in previous work. Scholarly resources for analyzing and writing up qualitative inductive research may acknowledge that even sole authors do not work entirely on their own, but critical questions about where to look for such help, who to engage, for what purpose, and at what time remain unanswered. As authors, moreover, qualitative inductive scholars often recognize in acknowledgment sections any help and support received, but we rarely share in full what really happened. How do others help us get from raw data through analysis, theorizing, framing, more analysis, more theorizing, and reframing to a paper and then to a published article? Through what venues do others amplify our excitement, alleviate our anxiety, end our despair, and cheer us on to keep going? 
Our chapter addresses these questions. We offer a comprehensive overview of the types of help qualitative inductive researchers receive, the people to whom they turn for help, and the process through which authors engage these individuals. Our motivation in doing so stems in part from our own experiences taking single authored qualitative inductive papers from data to publication. In graduate school together at Harvard, both of us were working on qualitative, inductive dissertations (Marya also included quantitative methods). To help one another with challenges we were facing in analyzing our data, we initiated regular research meetings to talk through our questions about the research process (often with a heavy dose of concerns and doubts). After graduating and moving on to separate institutions, we continued this practice, holding research calls every three weeks. Today, as mid-career scholars, we still hold these calls. They have been pivotal in the development of our own single authored qualitative studies, in addition to helping to advance our co-authored work.

Over the years, Špela has helped Marya devise new approaches to analyzing her data when her existing approaches were producing dead ends, she has been a partner in redesigning figures and tables and in thinking through the structure of findings sections, and she has been a careful and detailed critical reader in the later stages of paper development. Marya has helped Špela to stay on course by being an enthusiastic supporter, to reframe a research question that led her down a dead-end road, and to design additional analyses that would persuade reviewers of her findings' credibility. She also pointed her to published articles that served as models of a suitable structure for her manuscript, and she was a responsive and thorough friendly reviewer as the manuscript began to take its final shape.

The ideas in this chapter draw on our experiences with one another and with other helpers, as well as on detailed accounts from three other qualitative inductive researchers - 
Michel Anteby, Emily Heaphy, and Tammar Zilber - who each described the journey of one of their papers and the process by which they develop qualitative inductive papers more generally. We also incorporate insights from a focus group we convened with expert and novice qualitative inductive researchers who shared their experiences about the help they look for and receive on their journey from data to paper. Drawing out common themes from these varied accounts, we illuminate the broad range of helpers that authors engage - from "travel companions" who accompany the author on the entire journey to "concierges" who serve as process facilitators with very specific and clearly defined tasks that move the process along. We further provide insight into specific practices for effectively engaging each type of helper.

\section{The Journey}

As we work through the process of data analysis and writing, qualitative inductive researchers engage travel companions and other helpers in a variety of different tasks. First, we sometimes work with others as we analyze our data, getting help condensing raw data into more abstract chunks through coding or other mechanisms. Second, we engage others to help us uncover what ethnographer Leslie Perlow (personal communication) calls "the little t" - the story in our data that explains what happened and why. Third, we seek help in developing "the big T” - a theoretical framing and narrative that explains the conceptual implications of the story from the data. In doing so, we construct a "theorized storyline" (Golden-Biddle \& Locke, 2007), where we articulate our study's theoretical significance by establishing a gap in the existing literature that our study helps to fill. Fourth, we seek advice in establishing the structure of our paper, deciding what goes where to convincingly and credibly convey our story and our theoretical contribution. Several additional tasks are required in order to accomplish these things, and qualitative researchers seek help here as well. We need to hold ourselves accountable - to 
make sure that we are making progress. We need to be emotionally supported, as developing a qualitative paper can feel very lonely and emotionally taxing (Hoepfl, 1997; Wolcott, 2001). We need to make appropriate process choices, such as when to look for model papers, where and when to present our paper, who to talk to regarding framing. And finally, we need to effectively respond to our journal reviewers and editors - by making sure we understand what they are asking from us and then addressing these issues not only in the paper but also in the response letter.

Qualitative inductive researchers engage several types of helpers as they navigate these different components of the journey from data to paper. Some are true "travel companions," the fellow qualitative inductive researchers who constitute our community of practice and are with us from beginning to end. Others are "friends we are trying to make" - members of the wider academic audience we are seeking to engage with our paper. Still others serve as "customs officers.” These are the journal editors and reviewers who offer valuable guidance in helping us move from submitted to published manuscript, even as they serve as gatekeepers who get to decide whether we can bring our findings "home.” We also engage "natives” - informants from the field and experts in our empirical context who help us stay true to the phenomenon we are studying. Finally, we may seek help from one or more “concierges” - writing coaches, copy editors, and others who facilitate the analysis and writing process, often by holding us accountable or providing motivation. In the sections that follow, we elaborate on these different types of helpers and identify exemplary practices authors use to engage them. Figure 1 provides a summary.

Insert Figure 1 about here 


\section{Travel Companions (A Community of Practice of Qualitative Researchers)}

Even though we focus on sole-authors, they rarely travel alone. Each has a set of travel companions - fellow qualitative inductive researchers that accompany the author on the journey from raw data to a published article with an interesting story and a theoretical contribution. Experienced authors tend to have one or more individuals with whom they talk regularly - some daily, others bi-weekly or every three weeks - about their progress and their developing theory. These travel companions may be peer students or faculty, dissertation advisors, or trusted senior faculty colleagues. They may also include members of formal or informal qualitative inductive research groups in which authors participate, with the group splitting its time and focus among members' dilemmas and questions. Taken together, travel companions form an "inner circle" or "community of practice” on whom authors rely throughout the analysis and writing process.

Authors engage their travel companions for the length of the journey. They start early, when they have only developed the kernels of the emerging story or "little t" in the data. To engage others in this process, the author often provides a quick representation of the data or of data fragments - a picture, a table, a set of bullet points, a quotation - that serves as fodder for a conversation about interesting pieces of the data and possible storylines to draw out. These exchanges are helpful in part because they create an opportunity for the author to articulate emerging ideas from the data. In addition, they help the author learn what others think is interesting and new in the data and what could be further explored (cf. Locke, et al., 2008).

The travel companions who provide help developing the "little t" differ from the "peer debriefers” described by Given (2008) in that they need not be familiar with the phenomenon under study. It is critical, however, that these travel companions are intimately familiar with 
qualitative inductive research methods, particularly at this early stage in the analysis process. Until framing solidifies, feedback from quantitative scholars, while well-intentioned, can derail qualitative researchers. Because quantitative researchers tend to focus on explaining variance, their reactions and suggestions may steer qualitative researchers away from the types of research questions for which the method is best suited: deep explorations of phenomena and the processes and mechanisms that connect them. Suggestions from quantitative researchers sometimes prompt analyses that are counter-productive because they aim to explain variation rather than unpack processes. They can also introduce literatures in which it is difficult to make a contribution using qualitative, inductive methods because the phenomenon is already well understood. Such feedback can sometimes raise paralyzing doubts, particularly for junior scholars. In contrast, qualitative, inductive travel companions help build a safe space in which theory can be induced from the data.

In addition to engaging travel companions to help identify and refine the "little t," authors also turn to these individuals later in the process to help them find an appropriate framing for the paper. They do so by having frequent and regular in-depth conversations as well as obtaining feedback on full drafts of a paper. Even as travel companions offer guidance on framing, though, they need not be experts in the literature in which the research will eventually be situated, just as they are often not experts in the phenomenon. Finding someone who understands and is engaged in qualitative inductive research is most important. Trust is also essential: the author must feel comfortable revealing doubts and weaknesses in the emerging storyline, as surfacing and working through these issues is critical to strengthening the manuscript. Authors want their travel companions to be tough but constructive critics, willing to expose flaws and help the author figure out how to address them. Those who read full drafts may also address questions about the 
structure of the paper, such as what material belongs in the methods versus the findings section, how much of the findings to foreshadow in the introduction and framing of the paper, and in what order to present the findings.

Finally, authors turn to travel companions, particularly those who are more experienced, when they received journal editors' letters and formal reviews. At this stage, authors seek help interpreting what reviewers are saying, to understand what needs to be done and how to do it, as well as how to think through how to craft a response letter. Just as many authors share snippets of data with travel companions earlier in the process, some also share discrete paragraphs from an editorial decision or review, as a precursor to a conversation about how to address the particular issue raised. In contrast, other authors seek guidance on their overall approach to a revision and share the full editor's letter and all reviews.

Across all these stages of analysis and writing, travel companions are particularly wellsuited to provide emotional support. Because they are intimately familiar with the process, they understand the challenges and are well positioned to empathize and encourage. Indeed, several qualitative authors we spoke with described their travel companions as not just intellectual partners but also true friends who had the author's best interests at heart. Travel companions are also well positioned to provide process suggestions, something especially important for more junior qualitative inductive scholars. Suggestions might include advice about whether to write up a draft of findings first (to focus the analysis) or start with tables and figures (to focus the writing), as well as ideas about how to keep track of insights, where to turn for good model papers, when in the process to present the paper to a particular audience, and who could serve as an effective friendly reviewer. 


\section{Friends We Are Trying to Make (Wider Academic Audience)}

Writing inductive qualitative papers represents an imperative to "befriend" the wider academic audience. We must convince other researchers that our work is credible, relevant, and valuable. To do so, qualitative inductive authors engage individuals from multiple, increasingly broad circles of the wider academic audience with whom their research is in conversation. First, as they are developing their "big T" theoretical framing (and continuing to refine the "little t" story in the data), authors engage other qualitative researchers. They present their work at conferences attended primarily by other qualitative researchers and in departments with a qualitative research orientation. Through informal conversations and feedback on presentations, these audience members help the author continue to refine the "little t," and, more critically, contribute to shaping the framing or "big T" of a paper. For one author, the framing and ultimate title of a paper emerged in large part from comments made by two fellow qualitative inductive researchers at an informal feedback session during a conference. Authors also use these conferences and seminar presentations as deadlines that prompt them to articulate and focus their ideas within a particular time frame, even if full papers are not required.

In a related practice, some authors establish or join existing groups of qualitative inductive researchers who read and comment on one another's papers. We call these "feedback groups" to distinguish them from the "research groups" described earlier, which focus on sharing ideas and fragments of data much earlier in the process. Feedback groups represent one of the most intense and in-depth forms of help authors receive. Comments are often critical, even "harsh,” but members couple these with suggestions for how to improve the paper. The feedback received ranges from ideas about the "little t" to suggestions on the "big T," from comments on paper structure to help interpreting and responding to journal reviews. Authors often enter these 
meetings confused or ambivalent about the direction in which to take their paper but leave with a clear sense of next steps and the desired final destination. Self-organized groups of this nature tend to comprise qualitative researchers at similar stages of their career, often - but not always geographically co-located. Some authors also get help from feedback groups of which they are not regular members. For example, some senior colleagues we know have generously offered up their own feedback groups after one-on-one conversations in which a junior author sought their guidance.

Once the framing of the paper starts taking shape and the literature(s) in which the study will be framed and to which it will contribute become clearer, authors reach out to experts in those literatures for feedback and ideas. Their goal in doing so is to further refine the "big T" and craft a paper that will appeal to the desired audience. At this stage, authors tend to engage quantitative as well as qualitative scholars, with expertise in the literature being more important than expertise in the method. In order to not overburden these individuals, some authors choose to approach them with specific questions instead of asking them to read full drafts. Others seek out informal interactions with experts on particular literatures at conferences or in research groups instead of or in addition to asking for feedback on written text. Even seemingly cursory conversations can sometimes enable substantive progress, pointing authors to particularly relevant papers or helping them to more clearly articulate the gap in the literature.

As authors get ready to submit their work to journals, some engage an even broader audience, by circulating well developed full drafts to colleagues from their departments and other academics with whom they are friendly, with the aim of getting general feedback about how compelling and interesting the paper is and identifying any major flaws or "reviewer landmines" - issues that could aggravate or confuse reviewers and prompt a negative evaluation. This 
practice differs in important ways from the practice of asking "travel companions” to provide feedback on well-developed drafts. When circulating drafts to representatives of the wider academic audience, authors tend not to expose flaws and point out weaknesses, whereas they actively do so when engaging travel companions. The deep trust that exists with travel companions is not essential for this kind of help. Any active academic, preferably someone familiar with the targeted journal and willing to devote the time to reviewing a draft, can serve as a helper at this stage and for this purpose.

Finally, qualitative inductive researchers also get help from individuals with whom they never directly engage, a group one author described as an “imagined community.” They spend time thinking about the audience to whom they are trying to speak and the conversation they are trying to enter, to decide how best to appeal to them. They also study published qualitative inductive papers for ideas about structure, data representation, analysis, and even specific wording. In addition, they sometimes examine papers published by their handling editors in an attempt to decipher which types of paper structure appeal to that editor. Some authors also review published quantitative papers and general guidance on how to write those in order to more effectively appeal to the quantitative researchers in their audience.

\section{Customs Officers (Editors and Reviewers)}

To return home from our travels, we need to clear customs. Customs officers check the goods that we are bringing along and decide whether we can enter with them or not. Similarly, there are gatekeepers in publishing our research: journal editors and reviewers. Perhaps surprisingly, authors are often effusive in describing how extraordinarily helpful these people can be in the development of their papers. Experienced qualitative inductive researchers view themselves as working in collaboration with their reviewers and editor to co-create a paper, and 
they find this process to be extremely generative. As a result, for their initial submission they aim to craft a paper that is "good enough” to receive an invitation to revise and resubmit, but they fully expect the editor and reviewers' help in working through their ideas. As one author put it, “you dance with the reviewers who see promise” in order to get the paper into a publishable form.

Even editors and reviewers who reject a paper can sometimes be extremely helpful. Once authors get past the initial sting of a rejection, they are often able to strengthen their paper significantly based on the suggestions of those who did not see enough promise in the paper to invite a revision. Authors may also talk to the editor who rejected their paper, to seek clarification about what needs to change for the paper to be more convincing.

\section{Natives (Field Informants and Phenomenon Experts)}

A journey is much more memorable, and the story of the journey more compelling, if the traveler establishes meaningful relationships with those who live at the destination. Similarly, qualitative inductive researchers often go back to field informants from whom they collected data to gather reactions on their emerging findings and check for factual accuracy. Some also ask informants for feedback on framing and conclusions. Many authors feel deeply indebted to these individuals, whose help is usually invisible to a paper's final audience but often quite significant for the author. In addition to seeking feedback from informants in the field, authors engage experts on the phenomenon under study, including personal connections who are familiar with the setting as well as scholars from other disciplines, to gauge their reactions to the story and to check technical language. However, to avoid becoming co-opted and to maintain the required critical distance from their phenomenon, authors must balance the perspective of natives, particularly field informants, with help from other sources. 


\section{Concierge (Process Facilitators)}

On a trip, a good concierge can sometimes help more than all the well-intentioned friends combined. Similarly, experienced qualitative inductive researchers recognize that for some kinds of tasks, engaging process facilitators is the most effective way to go. In the early stages of the analysis process, authors sometimes engage research assistants (RAs) to help them work through the often tedious process of coding raw data. One author we spoke with uses RAs as a source of diversity, seeking out individuals who will become familiar with the data but who can offer a different point of view. Other authors, particularly those with a strong interpretive focus, feel strongly about doing the analysis themselves. They find it counter-productive to outsource coding to RAs because doing so prevents the author from fully engaging with and "feeling" the data. Even authors who do use RAs for help with coding distinguish this from the help they seek in developing an emerging storyline or "little t" - relying primarily on themselves and fellow qualitative inductive "travel companions" for the latter.

Further along in the journey from data to paper, process facilitators include copy editors, writing coaches, motivation coaches, and writing groups. Copy editors can serve two purposes. First, they improve one's writing and provide suggestions on how to improve the structure of the paper to clarify the message. To be able to provide this kind of help, it is important that the copy editor be familiar with academic writing. Second, copy editors can sometimes serve as a source of accountability and pacing. One experienced qualitative inductive author we spoke with prepays a copy editor and commits to a deadline for submitting a draft for editing. In this way, working with a copy editor can help an author make steady progress and complete work by a chosen deadline. Some authors also use writing coaches who are either hired directly or, more fortunately, provided by a publisher. These individuals advise authors on how to "chunk up" 
their work to prevent them from becoming overwhelmed, they hold authors accountable for their progress, and they help fine-tune their writing, offering advice on finding the right words and clarifying meaning, paragraph by paragraph. In addition to writing coaches, authors sometimes engage motivation coaches who provide structure and accountability and prevent feelings of being overwhelmed, thereby contributing to forward progress on a manuscript.

Writing groups constitute still another kind of process facilitator. Members of these groups often simply sit together at a specified time and location to provide social support for one another's writing. To hold one another accountable, some groups use “carrots” such as celebratory parties when a member submits a paper or finishes a draft; others use "sticks" such as donating to a cause the author abhors if the agreed upon writing is not completed. (This may raise ethical dilemmas if a contribution is actually made, but none of our informants knew of examples where the author did not complete the writing on time.) Some authors use online writing communities for the same purpose - to provide accountability and pacing and to offer company in the often lonely process of writing up a sole-authored paper. Given the nature of this support, the expertise of the other writers is not important, in contrast to the research groups and feedback groups discussed earlier.

\section{Crafting Your Own Journey}

Sole authors of inductive qualitative articles are not alone on their journey from data to published papers. To the contrary, they rely on a number of helpers, ranging from close friends and spouses who happen to be fellow qualitative inductive researchers to hired professionals whom authors did not know until they were hired. In this chapter, we sought to illuminate this broad range of helpers, the means by which authors engage them, and the forms of help they provide. 
In closing, we want to draw out a few key considerations for readers planning their own research journeys. First, the helpers we described differ in how critical and how supportive they are. It is up to the author to create a balance between people who help them move forward by highlighting the strengths of their work and those who point out its weaknesses and ways to improve it further. (Some excellent helpers can do both.) Supportive, friendly helpers are particularly essential early on, while more critical helpers are often engaged later in the process. Second, each author also has to figure out how many helpers to engage. Too many and the author can be pulled in too many different directions; too few, especially if they are powerful ones such as former advisors or esteemed senior researchers, and the author may struggle to find his or her own voice and direction. Third, authors adopt different approaches to engaging their helpers. Some make deliberate choices about who they ask and what they request, actively choosing some forms of help and rejecting others. Others, particularly more junior ones, do not know where to turn for help in the long and arduous journey from data to paper and often reactively accept whatever comes their way.

To illustrate the variety of paths individual authors take, we summarize in Table 1 how the five authors we studied in depth engaged others in their journey from data to paper. Our intention is that readers will draw from these ideas to chart their own journeys, engaging travel companions and other helpers on their unique path toward publication of exemplary qualitative inductive research.

Insert Table 1 about here 
In planning their journeys, readers should keep in mind that much of the help we describe in this chapter is mutual. Qualitative inductive researchers who help others create goodwill, so that they can count on others' help when they need it. In addition, the process of helping others affords a unique opportunity to hone the craft of research and writing. In the words of Tammar Zilber (personal communication), when examining others’ work “our emotional investment does not stand in the way of learning, as it might when it is our own work." That makes it easier to notice patterns, errors, and opportunities for improvement, and to learn from them. It is therefore important not only to seek out help but also to seize opportunities to help others. We hope our chapter provides a foundation for doing so in a more thoughtful manner. Happy travels! 
Figure 1: Types of Helpers and the Help they Provide*

\begin{tabular}{|c|c|c|c|c|c|c|c|c|}
\hline & & Co & elp & & & Proce & & \\
\hline & 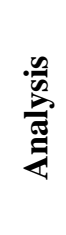 & (ِ & 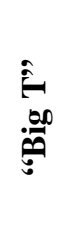 & 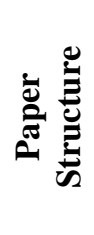 & 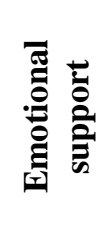 & 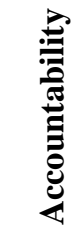 & 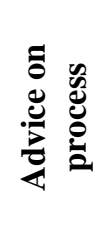 & 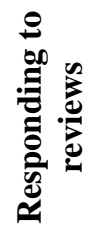 \\
\hline \multicolumn{9}{|l|}{$\begin{array}{l}\text { Travel Companions: Student peers, faculty } \\
\text { peers, senior faculty colleagues, dissertation } \\
\text { advisors, research groups }\end{array}$} \\
\hline \multicolumn{9}{|l|}{$\begin{array}{l}\text { Friends We Are Trying to Make: Feedback } \\
\text { groups, qualitative conference attendees, mixed } \\
\text { and quantitative conference attendees, audiences } \\
\text { at academic talks, literature experts, general } \\
\text { readers and representatives of the target journal's } \\
\text { audience, qualitative authors, quantitative } \\
\text { authors, authors within the same theory }\end{array}$} \\
\hline \multicolumn{9}{|l|}{$\begin{array}{l}\text { Customs Agents: Journal editors (including } \\
\text { rejecting editors), reviewers }\end{array}$} \\
\hline \multicolumn{9}{|l|}{$\begin{array}{l}\text { Natives: Informants from the field, phenomenon } \\
\text { experts }\end{array}$} \\
\hline $\begin{array}{l}\text { Concierge: Research assistants, copy editors, } \\
\text { writing coaches, motivation coaches, writing } \\
\text { groups }\end{array}$ & & & & & & & & \\
\hline
\end{tabular}

* Darker cells indicate more help received. 


\section{Table 1: Use of “Travel Companions” and other Helpers in Qualitative, Inductive Research}

\begin{tabular}{|c|c|c|c|}
\hline Reference & Research Context & Main three sources of help & Outcomes/Results \\
\hline Anteby, 2010 & $\begin{array}{l}\text { U.S. commerce in } \\
\text { cadavers }\end{array}$ & $\begin{array}{l}\text { Journal editor and reviewers } \\
\text { Qualitative researcher expert in } \\
\text { literature used to frame paper } \\
\text { Spouse who is a writer }\end{array}$ & $\begin{array}{l}\text { Suggested a new framing } \\
\text { Asked probing questions that the author then answered by further analysis } \\
\text { Provided inspiration - seeing his spouse write tirelessly without immediate } \\
\text { reward, the author is constantly inspired to keep moving forward }\end{array}$ \\
\hline Besharov, 2014 & $\begin{array}{l}\text { Socially responsible } \\
\text { retail company }\end{array}$ & $\begin{array}{l}\text { Regular conversations with } \\
\text { trusted qualitative researchers } \\
\text { Feedback groups } \\
\text { Journal editor and reviewers }\end{array}$ & $\begin{array}{l}\text { Provided help with "little t" and structure of the paper; offered feedback on } \\
\text { emerging model and full manuscript drafts } \\
\text { Helped craft strategy for responding to each round of reviews } \\
\text { Conversations with the editor confirmed and clarified approach to revisions; } \\
\text { reviewer comments illuminated key insights from the "little t" }\end{array}$ \\
\hline Heaphy, 2013 & $\begin{array}{l}\text { Patient advocates in a } \\
\text { hospital }\end{array}$ & $\begin{array}{l}\text { Dissertation advisor/senior } \\
\text { faculty colleague } \\
\text { Writing coach } \\
\text { Journal editor and reviewers }\end{array}$ & $\begin{array}{l}\text { Provided emotional support and process advice about how to make progress; } \\
\text { helped with response letter } \\
\text { Provided emotional support and pacing with writing; helped to identify what } \\
\text { writing needed clarification } \\
\text { Offered developmental feedback, including specific suggestions for } \\
\text { reframing and a list of citations }\end{array}$ \\
\hline Trefalt, 2013 & $\begin{array}{l}\text { Attorneys at a large law } \\
\text { firm }\end{array}$ & $\begin{array}{l}\text { Regular conversations with } \\
\text { trusted qualitative researchers } \\
\text { Journal editor and reviewers } \\
\text { Research group }\end{array}$ & $\begin{array}{l}\text { Provided accountability, helped with "little t" and structure of the paper, } \\
\text { helped to articulate the final framing } \\
\text { Helped with theoretical contribution and structure; helped focus the "little t" } \\
\text { Quantitative researcher proposed a literature that ended up being part of the } \\
\text { framing }\end{array}$ \\
\hline Zilber, 2011 & $\begin{array}{l}\text { High technology } \\
\text { conferences in Israel }\end{array}$ & $\begin{array}{l}\text { Regular conversations with } \\
\text { trusted qualitative researcher } \\
\text { Conference presentations } \\
\text { Journal editor and reviewers }\end{array}$ & $\begin{array}{l}\text { Helped identify "little t," "Big T,” and structure of paper; provided emotional } \\
\text { support, advice on process; helped interpret feedback, respond to reviewers } \\
\text { Crafting presentations helped clarify and focus the theoretical contribution, } \\
\text { conference deadlines provided accountability for developing a full paper } \\
\text { Suggested more transparent means of explaining data analysis process; } \\
\text { proposed theoretical hook for framing "little t” }\end{array}$ \\
\hline
\end{tabular}




\section{REFERENCES}

Anteby, M. (2010). Markets, morals, and practices of trade: Jurisdictional disputes in the U.S. commerce in cadavers. Administrative Science Quarterly, 55, 606-638.

Becker, H. S. (1998). Tricks of the trade : how to think about your research while you're doing it. Chicago, Ill.: University of Chicago Press.

Besharov, M. H.-P. (2014). The relational ecology of identification: How organizational identification emerges when individuals hold divergent values. Academy of Management Journal, 57, 1485-1512.

Carlson, A., \& Dutton, J. E. (Eds.). (2011). Research alive: Exploring generative moments in doing qualitative research. Copenhagen: Copenhagen Business School Press.

Given, L. M. (Ed.). (2008). The Sage encyclopedia of qualitative research methods (Vol. 2). Thousand Oaks, CA: SAGE Publications.

Glaser, B. G., \& Strauss, A. L. (1967). The discovery of grounded theory: Strategies for qualitative research. Hawthorne, N.Y.: Aldine de Gruyter.

Golden-Biddle, K., \& Locke, K. (2007). Composing qualitative research (2nd ed.). Thousand Oaks, CA: Sage.

Heaphy, E. D. (2013). Repairing breaches with rules: Maintaining institutions in the face of everyday disruptions. Organization Science, 24, 1291-1315.

Hoepfl, M. C. (1997). Choosing qualitative research: A primer for technology education researchers. Journal of Technology Education, 9, 1-16.

Locke, K., Golden-Biddle, K., \& Feldman, M. S. (2008). Making doubt generative: rethinking the role of doubt in the research process. Organization Science, 19, 907-918. 
Lofland, J., \& Lofland, L. H. (1995). Analyzing social settings: A guide to qualtiative observation and analysis. Belmont, CA: Wadsworth.

Pratt, M. G. (2009). For the lack of a boilerplate: Tips on writing up (and reviewing) qualitative research. Academy of Management Journal, 52, 856-862.

Strauss, A. L., \& Corbin, J. M. (1998). Basics of qualitative research: techniques and procedures for developing grounded theory (2nd ed.). Thousand Oaks: Sage Publications.

Trefalt, Š. (2013). Between you and me: Setting work-nonwork boundaries in the context of workplace relationships. Academy of Management Journal, 56, 1802-1829.

Van Maanen, J. (1988). Tales of the field: On writing ethnography. Chicago: University of Chicago Press.

Weiss, R. S. (1995). Learning from strangers: the art and method of qualitative interview studies (1st Free Press pbk. ed.). New York: Free Press.

Wolcott, H. F. (2001). Writing up qualitative research (2nd ed.). Thousand Oaks, CA: Sage.

Zilber, T. B. (2011). Institutional multiplicity in practice: A tale of two high-tech conferences in Israel. Organization Science, 22, 1539-1559. 